http://jmscr.igmpublication.org/home/ ISSN (e)-2347-176x ISSN (p) 2455-0450 crossref DOI: https://dx.doi.org/10.18535/jmscr/v8i3.59

\title{
Clinical Profile of Coronary Artery Disease Patients with Special Reference to Ear Lobe Crease and Ear Canal Hair
}

\author{
Authors \\ Dr S.V. Birajdar ${ }^{1}$, Dr Akshay V. Bharati ${ }^{*}$, Dr S.S. Chavan ${ }^{3}$, Dr S.A. Chaudhari ${ }^{4}$ \\ ${ }^{1}$ Professor \& HOD, Department of General Medicine, SRTR GMC, Ambajogai \\ ${ }^{2}$ Junior Resident, Department of General Medicine, SRTR GMC, Ambajogai \\ ${ }^{3}$ Associate Professor, Department of General Medicine, SRTR GMC, Ambajogai \\ ${ }^{4}$ Associate Professor, Department of General Medicine, SRTR GMC, Ambajogai \\ *Corresponding Author \\ Dr Akshay V. Bharati
}

Junior Resident, Department of General Medicine, SRTR GMC, Ambajogai, Maharashtra, India

\begin{abstract}
Background: The burden of coronary artery disease $(C A D)$ is on the rise globally \& we need simple and reliable physical signs to identify high risk individuals. There are very few studies related to prevalence of Ear lobe crease (ELC) \& Ear canal hair (ECH) and its association with CAD in Indian population.

Aim: To find out incidence of ear lobe crease and ear canal hair in patients of myocardial infarction \& their correlation with other known risk factor of myocardial infarction.

Materials \& Methods: It was an observational, cross-sectional study conducted in a rural tertiary care center consisting of two groups, study group consisting of 100 cases of myocardial infarction and control group consisting of 200 patients having disease other than coronary artery disease \& were studied for the presence of Ear lobe crease and ear canal hair and relation with other risk factors.

Results: The study group was divided into two groups, group A with known risk factors (78\%) \& group B with without known risk factors (22\%). In study group A,43.58\% had both ear lobe crease and ear canal hair while $29.5 \%$ had isolated ear lobe crease. In group B,31.8\% had both ear lobe crease and ear canal hair and isolated ear lobe crease. $74 \%$ of study participants and $16 \%$ of control group had ear lobe crease while $35 \%$ in study group and $6 \%$ of control group had ear canal hair. Incidence of death was more in group B (31.18\%) than in group A (14.10\%).

Conclusion: Incidence of complications and death was more in a group with known risk factors absent when compared with the group in which known risk factors were present, thus it can be concluded that ,ear lobe crease \& ear canal hair is not only an independent risk factor for coronary artery disease but also a bad prognostic indicator.

Keywords: Coronary artery disease, Ear lobe crease, Ear canal hair.
\end{abstract}

\section{Introduction}

Skin is the icing on the anatomical cake, and without it not only would we all look rather unappealing, but a variety of unpleasant physiological phenomena would bring about our demise (R. Graham Brown, 1996). Skin is thought to be the mirror of internal diseases because it gives clue for internal disease and helps in early diagnosis. 
The burden of coronary artery disease (CAD) is on the rise globally. Indian population is prone to develop CAD at a much younger age. Number of risk factors are blamed for Myocardial Infarction. These risk factors are diabetes mellitus, hypertension, type A personality, raised cholesterol, family history of ischaemic heart disease, chronic alcoholism, obesity, tobacco addictions, long term use of oral contraceptives etc. E Braunwald (1997) described number of skin manifestations, which are known to be associated with coronary artery disease like xanthomas, Necrobiosis lipoidica diabeticorum and dermopathia. ${ }^{(1)}$ For prevention of CAD, we need simple and reliable physical signs to identify high- risk individuals. The heart and skin have much in common due to common changes during aging and degenerative processes. $(2,3,4)$ The diagonal earlobe crease (DELC) is a line extending from the tragus toward the outer border of the earlobe. ${ }^{(5)}$ Association between DELC and CAD was first described by Frank in 1973. ${ }^{(6)}$ There are very few studies related to prevalence of DELC and its association with CAD in Indian population. ${ }^{(7,8)}$ Prevalence of ear lobe crease is often reported in the sixth to ninth decades of life. ${ }^{(9)}$ Presence of bilateral ear lobe crease often accompanied by vascular dysfunction ${ }^{(10)}$ Postmortem study confirmed the significant positive correlation between the presence of ear lobe crease and coronary heart diseases. The mechanism leading to the association of the ELC with $\mathrm{CAD}$ remains controversial. It is unknown whether ELC is linked to atherosclerosis by common genetic factors, as suggested by similar trends for the prevalence of ELC and CAD among some ethnic groups and by data derived from analysis of human leukocyte antigen subtypes, or if it is an acquired physical sign resulting from vascular disease, skin atrophy or changes in the connective tissue matrix. ${ }^{(11,12,13)}$ A recent literature review showed a correlation between Indian men with ear canal hair $(\mathrm{ECH})$ and ear lobe crease (ELC) with developing heart disease. ${ }^{(14)}$ Some investigators related it to the presence of tears in the elastic fibres of the earlobes, whereas others hypothesized that it was related to increased androgen activity. ${ }^{(15)}$

In developing country like India, 70\%-80\% population stays at rural setting with no laboratory investigations and no specialists available. In such situation, health workers and peripheral doctors can be trained. Presence of the ELC, a clinical marker can be easily noted by nonclinical or health workers may be used to identify person with high risk of IHD. We therefore investigated both ELC and ECH in Indian Population with the objectives of determining their demographic characteristics and clinical correlation, singly as well as combined with the occurrence of CAD.

\section{Materials and Methods}

It was an observational, cross-sectional study conducted in a rural tertiary care center. It included diagnosed cases of myocardial infarction admitted to ICU (Intensive care unit) and attending OPD (Outpatient Department).Patients were divided into two groups, study group consisting of 100 cases of myocardial infarction and control group consisting of 200patients having disease other than coronary artery disease. Duration of study was 18 months.

\section{Inclusion Criteria}

1. Diagnosed cases of myocardial infarction admitted in ICU \& attending the follow up OPD

2. Both male and female patients are included

3. Age between 15 to 60 years

4. Patient which fit the criteria to Define them as ear lobe crease positive

5. Patients willing to participate and willing to give informed consent.

\section{Exclusion Criteria}

1. Patients with sparse ear canal hair

2. Those patients who were admitted in ICCU and expired before investigation.

3. Patients unwilling to give written informed consent, patients who are uncooperative.

4. Age less than 15 years and more than 60 years. 
5. Patient does not fit the criteria to define them as ear lobe crease positive.

Permission to conduct the study and ethical clearance was obtained from the Institutional Ethics Committee. Patients were fully informed about the purpose, procedures, benefit of participation in the study through informed consent form. Participation in this study was voluntary. Patients were informed that all record pertaining to the study would be confidential.

The interview was conducted by the investigator after taking informed consent of the study subjects. Criteria for diagnosis of coronary artery disease were essentially that of WHO.

\section{A) Electrocardiographic Changes}

ST segment elevation of $1 \mathrm{~mm}$ or more in extremity leads and of $2 \mathrm{~mm}$ or more in chest leads were considered to be significant. Q waves acceptable for diagnosis were as follows.

Anterior: Q wave more than 0.03 seconds

Inferior lead: Q wave in lead III and avF wave more than 0.03 seconds or more than $25 \%$ of $\mathrm{R}$ wave height.

Lateral: Q wave in leads I and avL more than 0.03 seconds or more than $25 \%$ of $\mathrm{R}$ wave height

\section{B) Serum Enzymes}

Unequivocal changes consisted of serial changes or initial rise and subsequent fall of the serum enzyme level. The change must be properly related to the particular enzyme and to the delay in time between onset of symptoms and blood sampling. Equivocal changes consisted of an enzyme pattern were an initially elevated level was not accompanied by a subsequent form, the curve of enzyme activity was not obtained.

According to the above criteria, diagnosed cases of myocardial infarction admitted in intensive cardiac care unit (ICCU) and those patients coming to the OPD for follow up were taken for the study.

A complete history was obtained from the patients and relatives paying specific attention to age and risk factors for coronary artery disease. A detailed cardiovascular system examination was done, which was followed by systemic examination.All patients were examined in good light for cutaneous markers specifically ear lobe crease and ear canal hair.

All the cases were subjected to a battery of investigations i.e. fundus examination to find out evidence of hypertensive or diabetic retinopathies, blood sugar, blood urea, serum creatinine, serum cholesterol, aspartate aminotransferase (SGOT), alanine aminotransferase (SGPT) and other appropriate investigations.

Cases having ear lobe crease characterized by diagonal deep wrinkle in the lobar portion of one or both auricles extending for a distance greater than or equal to one third of the ear lobe length in sitting position were considered to be ear lobe crease positive.

Cases having ear canal hair which are terminal (deeply pigmented and stiff), numbering one or more, present at tragus and antitragus, but other than normal hair on either ear were considered to be ear canal hair positive cases.

To rule out disputes, three different opinions were taken and only when two or more observers confirmed positive ear lobe crease and positive ear canal hair, cases were considered positive cases.200 patients who were attending the Medicine OPD for disease other than coronary artery disease were taken as control cases for the study.

\section{Statistical Analysis}

All responses were tabulated by the investigator using Microsoft-Excel 2016 Software. Graphical representations were made wherever necessary. Data was analysed by using SPSS software version 25.0Statistical tools like Mean, Standard deviation, Proportions and percentages, Chi Square Test were used.

\section{Results}

In study group, 65 patients $(65 \%)$ were men and 33 patients $(33 \%)$ were women. Number of patients were more in 4th, 5th, and 6th decade. Most of the male and female patients were clustered in between 41-70 years of age i.e.76\%.In control group, 131 patients $(66 \%)$ were men and 
69 patients (34\%) were women. Number of patients were more in 4th, 5th and 6th decade. Most of the male and female patients were clustered in between 41-70 years of age i.e. $73 \%$.

Out of 100 patients from study group 51 patients (51\%) had type A personality, 44 patients (44\%) were tobacco habitual, 27 patients $(27 \%)$ were chronic alcoholics, 19 patients (19\%) were obese. Out of 100 patients 14 patients (14\%) were hypertensive and 11 patients $(11 \%)$ had diabetes mellitus.

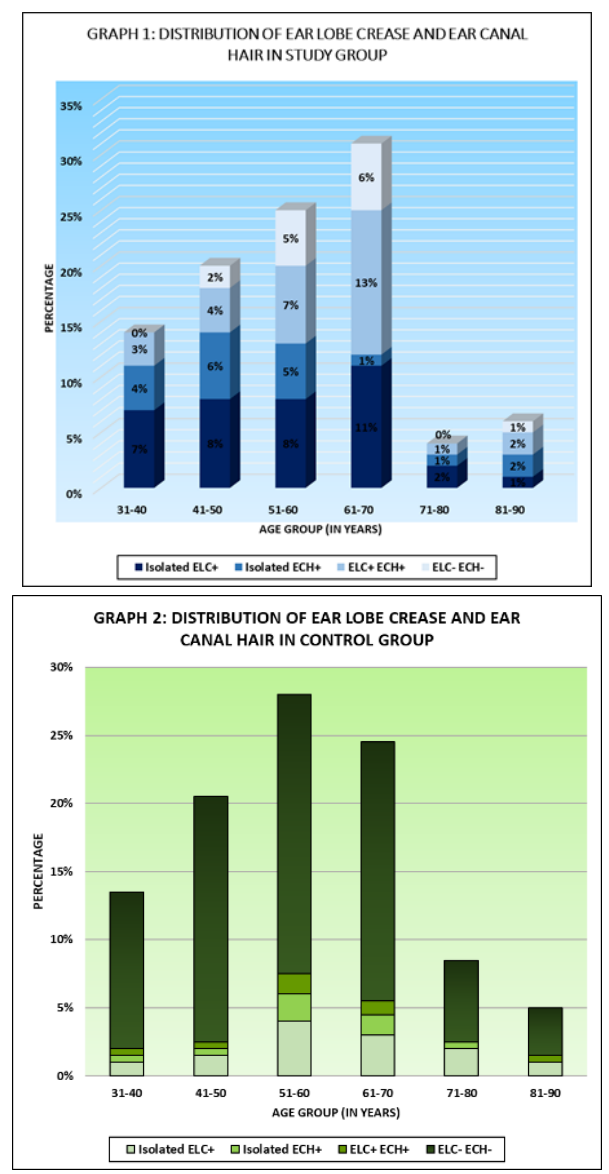

Graph 1 shows that in a study group out of 100 patients, 37 patients (37\%) had isolated ear lobe crease, 19 patients (19\%) had isolated ear canal hair. Ear lobe crease and ear canal hair both were present in 30 patients $(30 \%)$ while in 14 patients (14\%), both ear lobe crease and ear canal hair were absent. Most of the cases having ear lobe crease and ear canal hair were clustered between 41-70 years of age.
Graph 2 shows that in a control group out of 200 patients, isolated ear lobe crease was present in 25 patients $(12.5 \%)$, while isolated ear canal hair was present in 10 patients i.e. 5\%.Both ear lobe crease and ear canal hair both were present in 08 patients (4\%), while in 157 patients $(78.5 \%)$ had neither ear lobe crease nor ear canal hair. Most of the cases having ear lobe crease and ear canal hair were not clustered in the control group.

It was observed that out of 100 patients, $78 \%$ of patients in the study group showed risk factors which are known to cause Coronary Artery Disease and those were labelled as Group A while $22 \%$ patients did not show any risk factors and those were labelled as Group B patients.

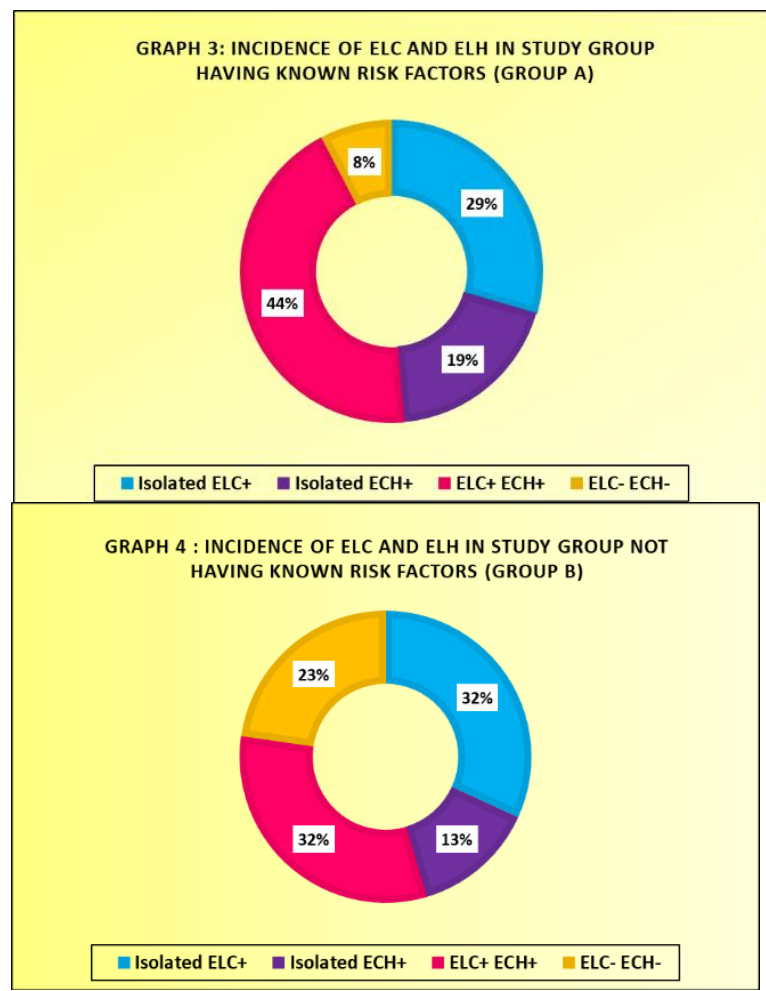

In graph 3 majority of the patients 34 (43.58\%) from study group having known risk factors, had both ear lobe crease and ear canal hair while isolated ear lobe crease was found in 23 cases (29.48\%). Whereas in graph 4, in patients without known risk factors, only 7 patients $(31.81 \%)$ had both ear lobe crease and ear canal hair and isolated ear lobe crease in 7 patients $(31.81 \%)$. 
Table No. 1: Incidence of ELC and ECH in individuals having known risk factors

\begin{tabular}{|l|c|c|c|c|c|}
\hline Risk factors & No. of cases & $\begin{array}{c}\text { Isolated } \\
\text { ELC+ }\end{array}$ & $\begin{array}{c}\text { Isolated } \\
\text { ECH+ }\end{array}$ & $\begin{array}{c}\text { ELC+ } \\
\text { ECH+ }\end{array}$ & $\begin{array}{c}\text { ELC- } \\
\text { ECH- }\end{array}$ \\
\hline Type A personality & 51 & 22 & 10 & 17 & 2 \\
\hline Tobacco habitual & 44 & 15 & 9 & 19 & 1 \\
\hline Chronic alcoholism & 27 & 12 & 6 & 7 & 2 \\
\hline Obesity. BMI>30kg/m & 19 & 9 & 4 & 6 & 0 \\
\hline Hypertension & 14 & 4 & 0 & 9 & 1 \\
\hline Diabetes mellitus heart & 11 & 2 & 2 & 7 & 0 \\
\hline $\begin{array}{l}\text { Family history of ischaemic } \\
\text { disease }\end{array}$ & 08 & 5 & 1 & 0 & 2 \\
\hline Raised serum cholesterol:>240mg\% & 04 & 3 & 2 & 0 & 1 \\
\hline $\begin{array}{l}\text { Oral contraceptive } \\
\text { pill use }\end{array}$ & 2 & 1 & 1 & 0 \\
\hline
\end{tabular}

$\mathrm{BMI}=$ body mass index ELC $+=$ Ear lobe crease present; ELC - = Ear lobe crease absent; ECH+ = Ear canal hair present; $\mathrm{ECH}-$ = Ear canal hair absent

Ear lobe crease was commonly observed in individuals having risk factors such as type A personality (39), tobacco habitual (34) and chronic alcoholism (19).Ear canal hair was commonly observed in individuals having risk factors such as type A personality (27), tobacco habitual (28).Both ear lobe crease and ear canal hair were found to be common in individuals having type A personality (17) and tobacco habitual (19). (table no.1)

Table No. 2: Incidence of ear lobe crease in study and control groups and its significance

\begin{tabular}{|l|c|c|}
\hline & $\begin{array}{c}\text { Study group } \\
(\mathrm{n}=100)\end{array}$ & $\begin{array}{c}\text { Control group } \\
(\mathrm{n}=200)\end{array}$ \\
\hline No. of patients with ELC & 74 & 32 \\
\hline No. of patients without ELC & 26 & 168 \\
\hline Total & 100 & 100 \\
\hline
\end{tabular}

$\mathrm{X}^{2}-98.15, \mathrm{p}<0.001$

In the study group, 74 (74\%) patients had ear lobe crease while in control group $32(16 \%)$ patients had ear lobe crease. In the study group $26(26 \%)$ patients did not have ear lobe crease while in the control group 168 (84\%) patients did not have ear lobe crease. By applying test of significance (Chisquare test) the probability was less than 0.001 i.e. highly significant.

(Table no.2)

Table No. 3: Incidence of ear canal hair in study and control groups and its significance.

\begin{tabular}{|l|c|c|}
\hline & $\begin{array}{c}\text { Study group } \\
(\mathrm{n}=100)\end{array}$ & $\begin{array}{c}\text { Control group } \\
(\mathrm{n}=200)\end{array}$ \\
\hline No. of patients with ECH & 35 & 12 \\
\hline No. of patients without ECH & 65 & 188 \\
\hline Total & 100 & 100 \\
\hline
\end{tabular}

$\mathrm{X}^{2}: 42.44, \mathrm{p}<0.001$

In the study group, 35(35\%) patients had ear canal hair while in control group $12(6 \%)$ patients had ear canal hair. In the study group 65 (65\%) patients did not have ear canal hair while in the control group 188 (94\%) patients did not have ear canal hair. By applying test of significance (Chisquare test) the probability was less than 0.001 i.e. highly significant. (Table no. 3) 
Table No. 4: Incidence of ear lobe crease and ear canal hair in study and control groups and its significance.

\begin{tabular}{|l|c|c|}
\hline & $\begin{array}{c}\text { Study group } \\
(\mathrm{n}=100)\end{array}$ & $\begin{array}{c}\text { Control group } \\
(\mathrm{n}=200)\end{array}$ \\
\hline No. of patients with ELC \& ECH & 42 & 22 \\
\hline No. of patients without ELC \& ECH & 58 & 178 \\
\hline Total & 100 & 200 \\
\hline $\mathrm{X}^{2}=61.06, \mathrm{p}<0.001$ & \multicolumn{2}{|l|}{}
\end{tabular}

In the study group, $42(42 \%)$ patients had both ear lobe crease and ear canal hair while in control group it was $22(11 \%)$ patients. In the study group $58(58 \%)$ patients did not have both ear lobe crease and ear canal hair while in the control group $178(89 \%)$ patients did not have both ear lobe crease and ear canal hair. By applying test of significance (Chi-square test) the probability was less than 0.001 i.e. highly significant. (Table no. 4)

Table No. 5: Incidence of death in group A and group B patients

\begin{tabular}{|l|c|c|c|}
\hline & Total & $\begin{array}{c}\text { Group A (Patients with known risk } \\
\text { factors for CAD) }\end{array}$ & $\begin{array}{c}\text { Group B (Patients without known } \\
\text { risk factors for CAD) }\end{array}$ \\
\hline Cases & 100 & 78 & 22 \\
\hline $\begin{array}{l}\text { No. of patients } \\
\text { Died }\end{array}$ & 18 & $11(14.10 \%)$ & $07(31.18 \%)$ \\
\hline ELC+ & & $08(72.72 \%)$ & $05(71.42 \%)$ \\
\hline ELC- & & $03(27.28 \%)$ & $02(28.58 \%)$ \\
\hline
\end{tabular}

ELC + = Ear lobe crease present; ELC- = Ear lobe crease absent; CAD = Coronary artery disease

Incidence of death was more in group B $(31.18 \%)$ than in group A (14.10\%). In both the group percentage of patients having ear lobe crease was more than the percentage of patients not having ear lobe crease. (Table no. 5)

\section{Discussion}

In our study majority of the patients were males both in study group (65\%) and control group (66\%). A study by Montazeri et al showed similar findings where $62.9 \%$ males were in study group and $44.7 \%$ males were in control group. $^{(16)}$ Bawaskar et al conducted a study among $60.4 \%$ males and $39.6 \%$ females which is similar to our study. ${ }^{(17)}$

We observed that Most of the male and female patients were clustered in between 41-70 years of age, $76 \%$ in study group and $73 \%$ in control group. A study by Kumar (2016) found that mean age of patients with DELC+ was $61.2 \pm 9.9$ years and DELC - patient was $51.9 \pm 11.3$ years. DELC+ patients were significantly older $(\mathrm{P}<$ $0.0001)^{(18)}$

We observed that among the patients from study group $51 \%$ had type A personality, $44 \%$ were tobacco habitual, $27 \%$ were chronic alcoholics, $19 \%$ were obese, $14 \%$ were hypertensive and $11 \%$ were diabetic. Bawaskar $\mathrm{H}$ et al observed that $18.4 \%$ consumed tobacco, $17.7 \%$ were obese, $72.7 \%$ were hypertensives, $54.8 \%$ had ischemic heart disease and $29.7 \%$ were diabetics. Our study correlates to the observations of Kadam et al where $6.15 \%$ participants had history of CAD, $10.1 \%$ were hypertensives and $12.5 \%$ were diabetics. $26.7 \%$ of patients were alcoholic in a study by Wu et al.

We found that $78 \%$ of patients in the study group showed risk factors which are known to cause Coronary Artery Disease and those were labelled as Group A while $22 \%$ patients did not show any risk factors and were labelled as Group B patients. This correlates to the study done by $\mathrm{Wu} \mathrm{X}$ et al, where $55.7 \%$ patients had CAD and $44.3 \%$ didn't have CAD. Sagar VT et al observed $19.6 \%$ patients suffered from CAD and $80.3 \%$ didn't have CAD, which was very dissimilar to our study. ${ }^{(19)}$

In our study group 37\% had isolated ear lobe crease while Sharma, in a study observed DELC in $98.7 \%$ of study subjects and $8.5 \%$ of controls. 
Shrestha et al observed ELC in $28.7 \%$ of the participants.

$19 \%$ patients had isolated ear canal hair. Ear lobe crease and ear canal hair both were present in 30 patients $(30 \%)$ while in 14 patients $(14 \%)$, both ear lobe crease and ear canal hair were absent. Most of the cases having ear lobe crease and ear canal hair were clustered between 41-70 years of age.

Kadam et al observed bilateral DELC was $2.7 \%$ in study group, DELC in males was $4.13 \%$ and $1 \%$ in females. The prevalence of DELC was significantly more common in males $(\chi=37.32, \mathrm{P}$ $=0.00$ ). In control group, it was seen to be $12.5 \%$, while isolated ear canal hair was present in $5 \%$. Both ear lobe crease and ear canal hair both were present in (4\%) patients, while in $78.5 \%$ had neither ear lobe crease nor ear canal hair. Majority of the patients $43.58 \%$ from study group A, had both ear lobe crease and ear canal hair while isolated ear lobe crease was found in $29.5 \%$. Whereas, in group B $-31.8 \%$ had both ear lobe crease and ear canal hair and isolated ear lobe crease.

Ear lobe crease was commonly observed in individuals having risk factors such as type A personality $^{(39)}$, tobacco habitual ${ }^{(34)}$ and chronic alcoholism $^{(19)}$ while ear canal hair was commonly observed in individuals having risk factors such as type A personality ${ }^{(27)}$, tobacco habitual ${ }^{(28)}$.

Both ear lobe crease and ear canal hair were found to be common in individuals having type $\mathrm{A}$ personality $_{(17)}$ and tobacco habitual ${ }^{(19)}$.

Sagar VT et al observed DELC in $77 \%$ of hypertensive patients, $85 \%$ of diabetics and $90 \%$ of CAD patients.

Montazeri et al observed a significantly higher frequency of smoking and hyperlipidemia in subjects with DELC. However, frequency of hypertension, diabetes and obesity were not significantly different.

The study showed also that subjects with DELC had more stenotic vessels and higher prevalence of both any and significant coronary artery stenosis than those without DELC ( $\mathrm{Wu}$ et al).
They also observed significant prevalence of alcoholism, hypercholesterolemia, but hypertension as a risk factor wasn't significant. Incidence of complication was more in group B (63.6\%) than group A (56.4\%). The number of patients having ear lobe crease was higher than those not having crease in both the groups.

In our study $74 \%$ of study participants and $16 \%$ of control group had ear lobe crease while $26 \%$ of study group and $84 \%$ in control group didn't have ELC. This was highly significant $(\mathrm{p}<0.001)$.

In our study $35 \%$ in study group and $6 \%$ of control group had ear canal hair. Further $65 \%$ of study participants and $94 \%$ of control group didn't have ear canal hair. This was highly significant $(\mathrm{p}<0.001)$.

Sharma et al in a study observed ear canal hairs in $49.7 \%$ of cases and $4.2 \%$ of controls. This was highly significant $(\mathrm{p}<0.001)$ and found to be associated with CAD. In our study group $42 \%$ and $5.5 \%$ in control group which was highly significant. $(\mathrm{p}<0.001)$

In a study by Kumar, ELC was observed in $42.7 \%$ of patients with coronary artery diseases. Kang $\mathrm{EH}$ et al in a study observed that $20.9 \%$ of subjects had ELC and it significantly increased with age. ( $p<0.0001)$. It could also suggest that with increasing age, the risk of atherosclerosis increases.

Incidence of death was more in group B $(31.18 \%)$ than in group A (14.10\%).

It was observed that 09 patients had myocardial infarction twice or more often. Out of these 09 patients, 5 patients $(55.55 \%)$ had both ear lobe crease and ear canal hair. Only one patient $(11.11 \%)$ had neither ear lobe crease nor ear canal hair.

\section{Conclusion}

Incidence of ear lobe crease \& ear canal hair was significantly more in study group than control group in all decades of life. Incidence of complications and death was more in a group with known risk factors absent when compared with the group in which known risk factors were 
present, thus it can be concluded that, ear lobe crease \& ear canal hair is not only an independent risk factor for coronary artery disease but also a bad prognostic indicator.

\section{References}

1. Dwivedi s, Jhanab R. Cutaneous markers of coronary artery disease. World $\mathrm{J}$ Cardio12010;2(9):262-9

2. Rahman K. Studies on free radicals, antioxidants, and co-factors. Clin Interv Aging 2007; 2(2):219-36

3. Gupta R. Recent trends in coronary heart disease epidemiology in India. Indian Heart J 2008; 60(2 SupplB):B4-18.

4. Begom R, Singh RB. Prevalence of coronary artery disease and risk factors in urban population of south and north India. Acta Cardiologica 1995; 50(3):227-40.

5. Rodríguez- López C, Garlito- Díaz H, Madroñero- Mariscal R, Sánchez- Cervilla PJ, Graciani A, López- Sendón JL, et al. Earlobe crease shapes and cardiovascular events. Am J Cardiol 2015;116:286- 93.

6. Frank ST. Aural sign of coronary- artery disease. N Engl J Med 1973;289:327- 8.

7. Nyboe J, Jensen G, Appleyard M, Schnohr P. Risk factors for acutemyocardial infarction in Copenhagen. I: Hereditary, educational andsocioeconomic factors. Copenhagen City heart study. Eur Heart J1989;10:910- 6.

8. Davis TM, Balme M, Jackson D, Stuccio G, Bruce DG. The diagonal earlobe crease (Frank's sign) is not associated with coronary artery diseaseor retinopathy in type 2 diabetes: The Fremantle diabetes study. Aust NZ J Med 2000;30:573- 7.

9. Lichstein E, Chadda KD, Naik D, Gupta PK. Diagonal ear- lobe crease: Prevalence and implications as a coronary risk factor. N Engl J Med 1974;290:615- 6.

10. Chen WC, Zhao TM, Xue W, Dong CL: Ear lobe crease, high serum cholesterol and human leukocyte antigen, risk factors in coronary artery disease. Chin Med J (Engl) 1982;95:839-842.

11. Kaukola S: The diagonal ear-lobe crease, a physical sign associated with coronary heart disease. AElliot WJ: Earlobe crease and coronary artery disease: 1,000 patients and review of the literature. Am $\mathrm{J}$ Med 1983;75:1024-1032.

12. Chen WC, Zhao TM, Xue W, Dong CL: Ear lobe crease, high serum cholesterol and human leukocyte antigen, risk factors in coronary artery disease. Chin Med J (Engl) 1982;95:839-842.

13. Pasternac A, Sami M: Predictive value of the ear crease sign in coronary artery disease. Can Med Assoc J 1982;126:645649.

14. Verma SK, Khamesra R, Mehta LK, Bordia A: Ear-lobe crease and ear-canal hair as predictors of coronary artery disease in Indian population. Indian Heart J 1989;41:86-91.

15. Shoenfeld Y, Mor R, Weinberger A, Avidor I, Pinkhas J: Diagonal earlobe crease and coronary risk factors. J Am Geriatr Soc 1980;27: 184-187.

16. Montazeri M, Montazeri M, Rashidi N, Montazeri M, Montazeri M. Diagonal earlobe crease and coronary artery disease in Iranian population: A marker for evaluating coronary risk. Indian J Otol [Internet]. 2014 Oct 1 [cited 2020 Feb 22];20(4):208-10. Available from: http://www.indianjotol.org/text.asp?2014/2 0/4/208/146941

17. Bawaskar H, Bawaskar P, Bawaskar P. Diagonal ear lobe crease: A premonitory diagnostic sign of impeding ischemic heart disease. J Fam Med Prim Care [Internet]. 2018 [cited 2020 Feb 22];7(6):1361. Available from: http://www.jfmpc.com/text.asp?2018/7/6/1 $361 / 246471$ 
18. Study To Evaluate The Freqency Of Diagonal Earlobe Crease As A Marker Of Coronary Artery Disease At Rims Ranchi., IJSR - International Journal of Scientific Research (IJSR), IJSR | World Wide Journals [Internet]. [cited 2020 Feb 22]

19. Wu X-L, Yang D-Y, Zhao Y-S, Chai W$\mathrm{H}$, Jin M-L. Diagonal earlobe crease and coronary artery disease in a Chinese population. BMC Cardiovasc Disord. 2014;14:43. 